\title{
Learning Analytics in K-12 Spanish education: a systematic mapping study
}

\author{
Belén Donate \\ GRIAL Research Group \\ Universidad de Salamanca \\ Salamanca, Spain \\ belendonateb@gmail.com
}

\author{
Francisco José García-Peñalvo \\ Dpt. de Informática y Automática \\ Universidad de Salamanca \\ Salamanca, Spain \\ fgarcia@usal.es
}

\author{
Daniel Amo \\ Dpt. of Engineering \\ La Salle, Universitat Ramon Llull \\ Barcelona, Spain \\ daniel.amo@salle.url.edu
}

\begin{abstract}
Learning analytics processes have an increased relevance in the digitization and virtualization of learning and teaching due to COVID-19, this analytical practice may mean improvements in K-12 levels in Spain. The work aims to expose the principal scientific publications regarding Learning analytics at these educational levels through a systematic mapping study. The authors set the hypothesis that there is limited research in such an educational context. Results validate the hypothesis and foster to continue the work through a deeper systematic review.
\end{abstract}

Keywords- Learning Analytics, K-12 education, mapping study, systematic review, learning metrics.

\section{INTRODUCTION}

In the Learning analytics field, Domínguez Figaredo, Reich, and Ruiperez-Valiente detect a gap between research and its transfer to educational practice [1], considering that the teachers that adopt LA in the classroom are only those that are researchers in this field. The latter is not entirely correct, as other authors [2] show how different teachers of K-12 Spanish education (without being researchers in LA) use and analyze educational data successfully but at a low level. However, these practices are isolated, not extended, and not standardized due to the lack of data literacy knowledge necessary to interpret or transform the analytical results of current digital educational tools, as pointed out by Domínguez Figaredo, Reich, and Ruiperez-Valiente [1] in their false assumption "educators already have the necessary literacy to understand the analytics provided by these tools or applications".

This lack of competencies in teachers contrasts with the high digitalization of schools in recent years. These radical changes in digital issues are due to the COVID-19 pandemic [3]-[6], whose reaction in education has been to introduce new educational practices strongly supported by connected and analytical digital tools [7], [8]. In line with the authors Domínguez Figaredo, Reich, and Ruiperez-Valiente [1], these new practices have revealed a lack of digital skills and data literacy in school teachers, including those at K-12 Spanish stages. Hence, it is reason enough to make learning analytics a significant and even necessary element in K-12 Spanish education.

Considering the above, the pandemic-educational context highlights the need to analyze the scientific advances of LA in the Spanish K-12 educational stage to extract challenges and opportunities for its transfer to practice. This work aims to understand the state of the art by conducting a systematic mapping study from 2018, a year before the COVID-19 pandemic. Considering that
Dominguez Figaredo, Reich, and Ruiperez-Valiente [1] affirm that only researchers in LA are those who transfer scientific knowledge to educational practice and that there are very few researchers in LA as teachers, it is formulated as an initial hypothesis that there is a small number of scientific publications in the Spanish K-12 stages.

Therefore, this paper aims to obtain an overview of the framework. For this purpose, the ideal method is systematic mapping, which provides baselines to assist futures research efforts [11].

The present work is organized into four sections. The first and current section serves as the introduction. The second section introduces the methodology, where the phases and steps followed for the development of this systematic mapping are specified. The third section presents the derived results. Finally, the fourth section exposes the discussion on the results found and the conclusions drawn.

\section{METHOD}

This section describes the method of the present systematic mapping. For its development, the methodology proposed by Kitchenham and Charters [9] and GarcíaHolgado, Marcos-Pablos, and García-Peñalvo [10] have been chosen. As these authors point out, mapping studies can benefit professionals as they provide a baseline for subsequent systematic reviews of the literature [11]. Besides, given the interdisciplinarity in the development of this type of work, this author encourages its use through the following stages [12]: (1) Construct questions that can be answered, (2) Search for evidence to answer these questions, (3) Critically evaluate the evidence, and (4) Use the evidences to answer the questions.

\section{A. Mapping Questions}

The following mapping questions (MQs) are contextualized in the K-12 stages of the Spanish territory. These have been set to delve into the problem detected.

- MQ1. How many studies have been published in the last four years?

- MQ2. Who are the authors of the articles included?

- MQ3. What is the country of origin of the authors?

- MQ4. What publication channels are the most prominent in the dissemination of articles?

- MQ5. Which domains have more publications?

- MQ6. What research methods have been used? 


\section{B. Inclusion and Exclusion Criterias}

The criteria used to include or exclude a work are organized into six inclusion criteria (CI) and six exclusion criteria (EC). The CI is defined such as: Articles published in journals, conferences, and books (IC1), Empirical research (IC2), Full text available (IC3), Impact on K-12 Institutes or Schools (IC4), Sample of centers education in the Spanish territory (IC5), and Publications between 2018 and 2021 (IC6). The EC is defined such as: Reports, dissertations, government, or other documents (EC1), Second-order investigations (EC2), Incomplete or unavailable text (EC3), Learning contexts based on nonregulated or non-K-12 training (EC4), Sample of educational centers outside the Spanish territory (EC5), and Publications before 2018 (EC6).

Electronic databases are chosen considering the following requirements are chosen: (1) logical expressions can be used in searches, (2) allows you to search in specific fields, (3) it is available to researchers through institutions, and (4) it is one of the most relevant in the research area of interest of this mapping process. Therefore, the search is conducted in the electronic databases Web of Science and Scopus. Additionally, the searches have been extended to Dialnet and Eric.

\section{Research Strategy}

An initial refinement has been carried out homogeneously across all databases (view Fig. 1), based on the date of publication, publishing channel, and the use of search criteria that allow access to a broader range of documents. Furthermore, the searchers have been carried out independently of the language.

The Boolean operators AND and OR have been used to combine the different search terms. These allowed the construction of research chains that contain four words simultaneously (AND) and the combination of words representing the same concept $(\mathrm{OR})$.

TABLE I.

RESEARCH CHAIN

\begin{tabular}{|c|c|c|}
\hline \multirow{2}{*}{ Database } & \multicolumn{2}{|l|}{ Searches and results } \\
\hline & Search string & Results \\
\hline \multirow{2}{*}{$\begin{array}{l}\text { Web of } \\
\text { Science }\end{array}$} & $\begin{array}{l}\mathrm{TS}=\quad \text { (learning AND analytics AND } \\
\text { secondary AND education) OR TS= } \\
\text { (learning AND analytics AND primary AND } \\
\text { education) }\end{array}$ & 78 \\
\hline & $\begin{array}{l}\mathrm{TS}= \\
\text { (learning AND analytics AND education AN } \\
\text { D "high school") OR TS= (learning } \\
\text { AND analytics AND education AND school) }\end{array}$ & 131 \\
\hline \multirow{2}{*}{ Scopus } & $\begin{array}{l}\text { TITLE-ABS-KEY ("Learning analytics" } \\
\text { AND secondary AND education) OR } \\
\text { TITLE-ABS-KEY ("Learning analytics" } \\
\text { AND primary AND education) }\end{array}$ & 62 \\
\hline & $\begin{array}{l}\text { TITLE-ABS-KEY ("Learning analytics" } \\
\text { AND "high school”) } \\
\text { OR TITLE-ABS-KEY ("Learning analytics" } \\
\text { AND school) }\end{array}$ & 209 \\
\hline \multirow{2}{*}{ Dialnet } & $\begin{array}{l}\text { Contiene palabras = (Learning AND analytics } \\
\text { AND secondary AND education) } \\
\text { OR (learning AND analytics AND primary } \\
\text { AND education) }\end{array}$ & 8 \\
\hline & $\begin{array}{l}\text { Contiene palabras= (learning AND analytics } \\
\text { AND education AND "high school") OR } \\
\text { (learning AND analytics AND education } \\
\text { AND school) }\end{array}$ & 16 \\
\hline ERIC & $\begin{array}{l}\text { SU ( "learning analytics") AND SU } \\
\text { (secondary school OR secondary education) }\end{array}$ & 199 \\
\hline
\end{tabular}

\begin{tabular}{|l|l|l|}
\hline \multirow{2}{*}{ Database } & \multicolumn{3}{|c|}{ Searches and results } \\
\cline { 2 - 4 } & \multicolumn{3}{|c|}{ Search string } & Results \\
\hline & $\begin{array}{l}\text { OR SU (primary school OR primary } \\
\text { education) }\end{array}$ & \\
\hline
\end{tabular}

\section{Selection process}

For the selection articles process, the phases proposed by PRISMA were followed [13] (View Fig. 1).

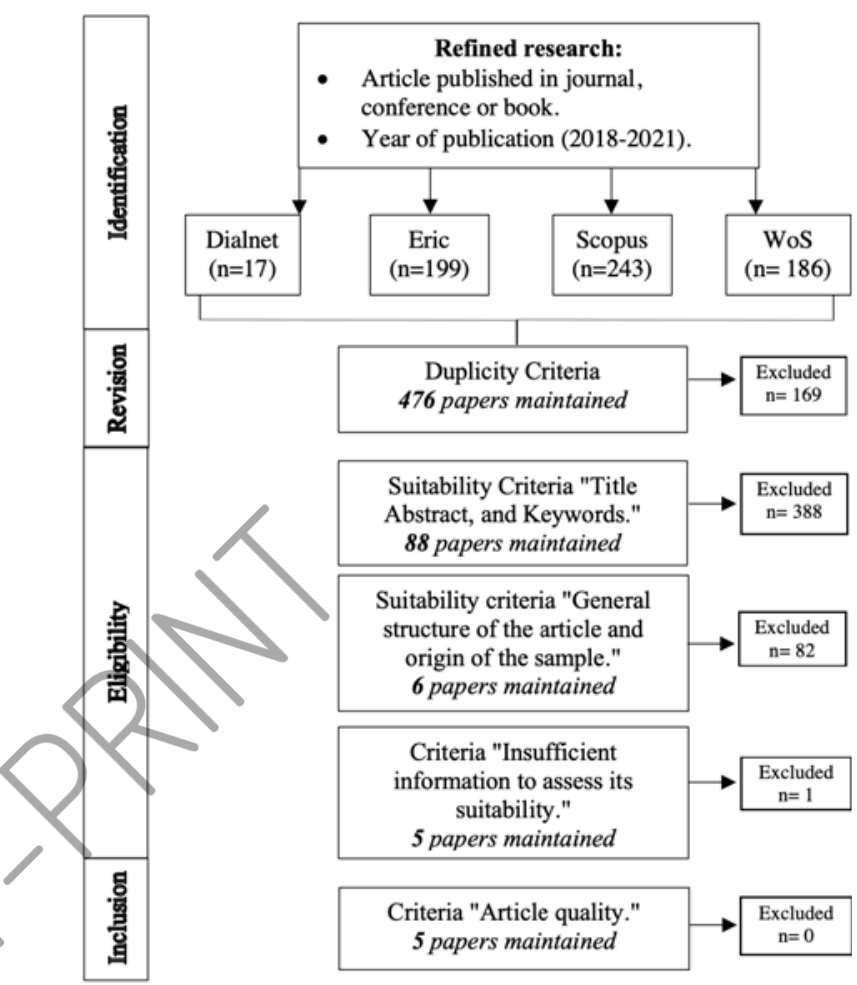

Fig. 1. PRISMA Flow Diagram.

Firstly, article identification has been carried out, obtaining a series of records through the execution of searches and initial refinement. This initial process has been developed homogeneously, adapting to the filtering parameters available in each database. For this reason, only "journal articles" have been selected in ERIC, with additional filters applied to the level of education. Afterward, duplicates have been discarded via Mendeley.

Subsequently, bibliographic eligibility has been assessed following the inclusion and exclusion criteria. For that, a first approach has been made to evaluate the abstract, title, and keywords. Later on, carrying out a deeper reading, delving into the structure and content of the works. In addition, those articles whose access was restricted or did not have sufficient information to assess their adequacy have been excluded.

Finally, an assessment was made of the quality of the information, verifying its systematicity and thoroughness. So lastly, five papers were included for analysis.

\section{RESULTS}

In this section, a descriptive analysis of the selected papers has been performed to answer the mapping questions. Table II shows the essential information of the selected articles sorted alphabetically by first author. 
TABLE II. SELECTED PAPERS

\begin{tabular}{|c|c|c|c|}
\hline Cite & Title & Authors & Year \\
\hline [14] & $\begin{array}{l}\text { Data Capture and Multimodal } \\
\text { Learning Analytics Focused } \\
\text { on Engagement with a New } \\
\text { Wearable IoT Approach }\end{array}$ & $\begin{array}{l}\text { V. Camacho, E. } \\
\text { Guia, T. Olivares, } \\
\text { M. Julia Flores, and } \\
\text { L. Orozco-Barbosa }\end{array}$ & 2020 \\
\hline [15] & $\begin{array}{l}\text { Fundamentos de diseño de un } \\
\text { entorno tecnológico para el } \\
\text { estudio de las habilidades en } \\
\text { resolución de problemas en } \\
\text { primeras edades escolares }\end{array}$ & $\begin{array}{l}\text { P. Diago Nebot, J. } \\
\text { González-Calero } \\
\text { Somoza, D. Arnau } \\
\text { Vera. }\end{array}$ & 2019 \\
\hline [16] & $\begin{array}{l}\text { Assessment of the Effects of } \\
\text { Digital Educational Material } \\
\text { on Executive Function } \\
\text { Performance }\end{array}$ & $\begin{array}{l}\text { N. Lara Nieto- } \\
\text { Márquez, } \\
\text { Cardeña Martínez, } \\
\text { A. Baldominos, A. } \\
\text { González Petronila, } \\
\text { and M. Á. Pérez } \\
\text { Nieto }\end{array}$ & 2020 \\
\hline [17] & $\begin{array}{l}\text { Teacher-led inquiry in } \\
\text { technology-supported school } \\
\text { communities }\end{array}$ & $\begin{array}{ll}\text { K. Michos, } & \text { D. } \\
\text { Hernández-Leo, } & \text { L. } \\
\text { Albó. } & \end{array}$ & 2018 \\
\hline [17] & $\begin{array}{l}\text { Diseño de un estudio } \\
\text { exploratorio para la } \\
\text { aplicación de técnicas de } \\
\text { analíticas de aprendizaje en la } \\
\text { enseñanza de las fracciones en } \\
5^{\circ} \text { curso de Educación } \\
\text { Primaria }\end{array}$ & $\begin{array}{l}\text { J. Rodríguez, J. } \\
\text { González, R. Cózar } \\
\text { Gutiérrez. }\end{array}$ & 2018 \\
\hline
\end{tabular}

Answering MQ1, five articles published between 2018 and 2021 have been selected. Two papers have been published per year, except for 2019, when only one work was published, and 2021, with no publications.

Regarding MQ2, Table III shows that there aren't inequalities in the level of activity of each author or continuity in the development of work in the learning analytics field for these educational levels can be identified.

TABLE III. AUTORS AND NUMBER OF PUBLICATIONS

\begin{tabular}{|l|c|}
\hline \multicolumn{1}{|c|}{ Names } & Total \\
\hline V. L. Camacho; E. D. La Guia; T. Olivares; M. Julia Flores; L. & \\
Orozco-Barbosa; P. D. Diago; J. A. González-Calero; D. Arnau; & \\
D. A. Filvà; M. A. Forment; F. J. García-Peñalvo; D. Fonseca & \multirow{2}{\text{Escudero;M.J.Casañ;N.LaraNieto-Márquez;A.Cardeña}}{} \\
Martínez; A. Baldominos; A. González Petronila; M. Á. Perez & 1 \\
Nieto; K. Michos; D. Hernández-Leo; L. Albó; J.A. Rodríguez; & \\
J. A. González-Calero; R. Cózar & \\
\hline
\end{tabular}

In respect of MQ3, all the authors of the selected articles come from Spanish universities. Concerning MQ4, the only channel found was the publication in educational or educational technology journals.

On the other hand, most of the papers found have got a sample located in Primary Education and combination with Secondary Education (View Fig 2).

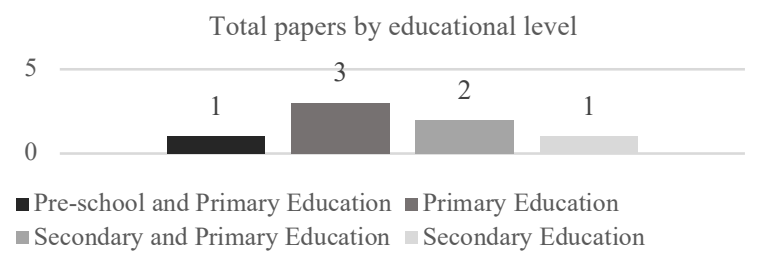

Fig. 2. Education levels of the samples.
To answer MQ6, the categorization recommended by Kitchenhman and Charters [11] for identifying the type of research developed by Wieringa, Mal. [18] has been chosen:

TABLE IV. PAPERS TYPES.

\begin{tabular}{|l|l|}
\hline \multicolumn{1}{|c|}{ Cite } & \multicolumn{1}{c|}{ Paper type } \\
\hline$[14]$ & Validation research \\
\hline$[15]$ & Solution proposal \\
\hline$[15]$ & Validation research \\
\hline$[16]$ & Experience paper \\
\hline$[17]$ & Validation research \\
\hline
\end{tabular}

Of the five studies included, three of them are validation research. Specifically, these are quasi-experimental, carried out in the natural context of the school. In addition, a proposed solution has been incorporated, consisting of a pilot study aimed at validating instruments for the development of learning analytics and establishing possible difficulties in their implementation. It's relevant to point out that some of these studies have not preserved the representativity of the sample, thus reducing the solidity and validity of the results. So, these warrant caution.

In addition, an experienced paper has been included [16] which is a multiple case study. This research methodology is defined by a systematic analysis of cases that reflect teaching experiences.

\section{DisCUSSION AND CONCLUSION}

The COVID-19 had a required digitalizing boost effect of the K-12 Spanish education. In this forced digitalized educational context, LA could take advantage of new digital traces of students and improve teaching and learning processes. However, there is a gap in the transfer of research from LA to educational practice [1]. In the same sense, only research professors in this field are those who carry out the transfer. Under these premises, the authors of the present manuscript (1) aim to understand the state of the art in the field of LA and K-12 Spanish education by conducting a systematic mapping study, and (2) establish the hypothesis that there will be little related scientific literature.

The reduced number of articles found shows that research on LA is still emerging in Spanish K-12 stages. The incipient nature of research in learning analytics at these educational levels has been evidenced in the results obtained in the MQs. A small number of works are extracted from them from 2018 to 2021 , dates justified by the great increase in digitization and the need to obtain a framework before the COVID-19 pandemic. This indicates that the state of the investigation is still incipient and there is no continuity and depth in the authors' investigations. This idea is reinforced by the exploratory characteristics of the observed empirical methods: quasi-experimental designs, pilots and case studies (MQ6).

Following the above, it should be noted that no international collaborations have been observed between researchers that could enrich the research of LA in Spanish territory considering K-12 stages (MQ3). In addition, in recent years, it has been observed that in researching on LA in the K-12 Spanish context, there is a tendency to choose a 
sample located in Primary Education and Secondary Education (MQ5).

The main limitations of this work include: (1) the established time interval, since it may not reflect the current situation of research in the field of learning analytics in Spanish K-12 stages, and (2) the rigidity of inclusion and exclusion criteria. Along these lines, although the interest resides in research and the transfer to the practice of LA at K-12 Spanish educational levels, it is understood that expanding the geographic range to other samples of students could provide a complete vision of the state of LA at these levels. In this sense, beyond the Spanish context, there have been studies that place the future of LA in the development of platforms that allow the performance of the teachinglearning process centered on emotions, awareness, communication and collaboration. [19]

As indicated by Kitchenham, Budgen, and Pearl [11], mapping studies can be a useful starting point for investigating research trends and the development of future systematic reviews. In this sense, despite the low volume of publications found in this work, the results foster to continue the present work through a systematic review of the literature in depth. To bypass limitations, increasing the search range from 2018 to 2010 (the year when the LA term was established) will allow obtaining a vision of more specific aspects, such as the degree of penetration and adoption of LA, or the techniques and methods used for its development.

\section{ACKNOWLEDGMENT}

The research that has led to these results has been carried out using funds from Fundació "la Caixa" (grant 2020URL-IR2nQ-004).

\section{REFERENCES}

[1] D. Dominguez Figaredo, J. Reich, and J. A. Ruiperez-Valiente, "Learning analytics and data-driven education: A growing field," Ried-Revista Iberoamericana De Educacion a Distancia, vol. 23, no. 2, pp. 33-43, 2020.

[2] S. Montaner Villalba, "Reseña del librø: Analítica del aprendizaje. 30 experiencias con datos en el aula," Edutec. Revista Electrónica de Tecnología Educativa, no. 67, 2019, doi: 10.21556/edutec.2019.67.1257.

[3] F. García-Peñalvo and A. Corell, "La COVID-19: enzima de la transformación digital de la docencia o reflejo de una crisis metodológica y competencial en la educación superior?," Campus Virtuales, vol. 9, no. 2, pp. 83-98, 2020. Accessed: Jul. 28, 2021. [Online]. Available: www.revistacampusvirtuales.es

[4] F. J. García-Peñalvo, A. Corell, V. Abella-García, and M. Grande, "Online assessment in higher education in the time of COVID-19," Education in the Knowledge Society, vol. 21, Jan. 2020, doi: 10.14201/eks.23013.

[5] F. J. García-Peñalvo, A. Corell, V. Abella-García, and M. Grande-dePrado, "Recommendations for Mandatory Online Assessment in Higher Education During the COVID-19 Pandemic," Lecture Notes in Educational Technology, pp. 85-98, 2021, doi: 10.1007/978-98115-7869-4_6.

[6] H. Fardoun, C. González, C. A. Collazos, and M. Yousef, "Estudio exploratorio en iberoamérica sobre procesos de enseñanzaaprendizaje y propuesta de evaluación en tiempos de pandemia," Education in the Knowledge Society, vol. 21, 2020, doi: 10.14201/eks.23437.

[7] F. J. García-Peñalvo, "Avoiding the Dark Side of Digital Transformation in Teaching. An Institutional Reference Framework for eLearning in Higher Education," vol. 13, p. 2023, 2021, doi: $10.3390 / \mathrm{su} 13042023$.

[8] F. J. Garcia-Penalvo, R. R. O. Rector, M. J. Rodriguez-Conde, and N. Rodriguez-Garcia, "The institutional decisions to support remote learning and teaching during the COVID-19 pandemic,” Dec. 2020. doi: 10.1109/JICV51605.2020.9375683

[9] B. Kitchenham, B. Kitchenham, and S. Charters, "Guidelines for performing Systematic Literature Reviews in Software Engineering,” 2007, Accessed: Jul. 27, 2021. [Online]. Available: https://citeseerx.ist.psu.edu/viewdoc/summary?doi=10.1.1.117.471

[10] A. García-Holgado, S. Marcos-Pablos, and F. García-Peñalvo, "Guidelines for performing Systematic Research Projects Reviews," International Journal of Interactive Multimedia and Artificial Intelligence, vol. 6, no. 2, p. 9, 2020, doi: 10.9781/IJIMAI.2020.05.005.

[11] B. A. Kitchenham, D. Budgen, and O. Pearl Brereton, "Using mapping studies as the basis for further research - A participantobserver case study," Information and Software Technology, vol. 53, no. $6, \quad$ pp. 638-651, 2011, doi: https://doi.org/10.1016/j.infsof.2010.12.011.

[12] B. A. Kitchenham, T. Dybå, and M. Jørgensen, "Evidence-based software engineering," Proceedings - International Conference on Software Engineering, vol. 26, pp. 273-281, 2004, doi: 10.1109/ICSE.2004.1317449.

[13] B. Hutton, F. Catalá-López, and D. Moher, "The PRISMA statement extension for systematic reviews incorporating network metaanalysis: PRISMA-NMA," Medicina Clínica, vol. 146, no. 6, pp. 262-266, 2016, doi: 10.1016/j.medcle.2016.10.003.

[14] V. L. Camacho, E. D. La Guia, T. Olivares, M. Julia Flores, and L. Orozco-Barbosa, "Data Capture and Multimodal Learning Analytics Focused on Engagement with a New Wearable IoT Approach," IEEE Transactions on Learning Technologies, vol. 13, no. 4, pp. 704-717, 2020, doi: 10.1109/TLT.2020.2999787.

[15] P. D. Diago, J. A. González-Calero, and D. Arnau, "Fundamentos de diseño de un entorno tecnológico para el estudio de las habilidades en resolución de problemas en primeras edades escolares," Research in Education and Learning Innovation Archives, no. 22, p. 60, 2019, doi: 10.7203/realia.22.14113.

[16] K. Michos, D. Hernández-Leo, and L. Albó, "Teacher-led inquiry in technology-supported school communities," British Journal of Educational Technology, vol. 49, no. 6, pp. 1077-1095, 2018, doi: 10.1111/bjet.12696.

17] J. A. Rodríguez, J. A. González-Calero, and R. Cózar, "Diseño de un estudio exploratorio para la aplicación de técnicas de analíticas de aprendizaje en la enseñanza de las fracciones en $5^{\circ}$ curso de Educación Primaria/ Design of an exploratory study for the application of learning analytical techniques in the ," Magister, vol. 30, no. 1, p. 29, 2018, doi: 10.17811/msg.30.1.2018.29-42.

[18] R. Wieringa, N. Maiden, N. Mead, and C. Rolland, "Requirements engineering paper classification and evaluation criteria: a proposal and a discussion," Requirements Engineering 2005 11:1, vol. 11, no. 1, pp. 102-107, Nov. 2005, doi: 10.1007/S00766-005-0021-6.

[19] C. A. Collazos, H. Fardoun, D. Alsekait, C. S. Pereira, and F. Moreira, "Designing Online Platforms Supporting Emotions and Awareness," 2021, doi: 10.3390/electronics10030251. 